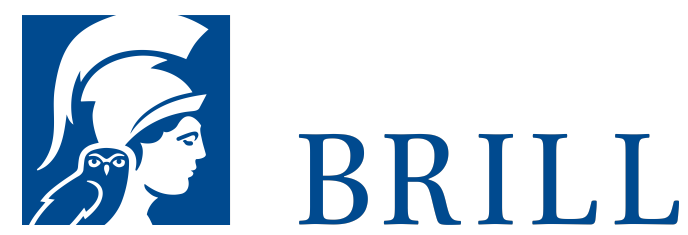

\title{
Verteilungsgerechtigkeit im Gesundheitswesen
}

Eine ethische Auseinandersetzung mit der Rationierungsdebatte

Author: Corinna Rubrech

Die Gesundheitssysteme westlicher Industrienationen werden aufgrund sozialer Umbrüche und technologischer Errungenschaften an die Grenzen ihrer Leistungsfähigkeit gelangen. Die Ursachen dafür liegen in der demografischen Alterung entwickelter Industrienationen und dem teuren medizinisch-technischen Fortschritt, der neue Behandlungsmöglichkeiten eröffnet. Zugleich führt eine dauerhaft niedrige Geburtenrate dazu, dass der Anteil der Beitragszahler in der Bevölkerung abnimmt. Die Schere zwischen dem medizinisch Sinnvollen und dem ökonomisch Machbaren geht weiter auseinander. Schon jetzt ist eine Maximalversorgung für alle Mitglieder der Gesellschaft nicht mehr möglich. Eine Begrenzung der medizinischen Versorgung ist deshalb unumgänglich und findet bereits statt - allerdings verdeckt und ohne klar definierte Standards. In diesem Buch wird deshalb zum einen eine moralische Kosten-NutzenAnalyse begründet, die eine Rangreihenbildung zwischen verschiedenen Gesundheitsleistungen erlaubt. Zum anderen werden ausgewählte Kriterien kritisch untersucht, anhand derer eine Prioritätensetzung zwischen verschiedenen Personengruppen möglich wird.

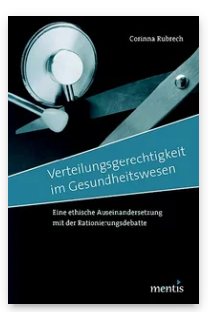

Pages: 190 Seiten Language: German Subjects: General, Philosophy

Publisher: Brill | mentis

E-Book (PDF) Released online: 15 Jun 2016 ISBN: $978-3^{-}$ 95743-875-1 List price Paperback Publication date: o8 Jun 2016 ISBN: 978-395743-059-5 List price 
For more information see brill.com

Order information: Order online at brill.com +44330 333 0049 | customerservices@brill.com Submission information: brill.com/authors

Titles published by Brill | Fink, Brill | mentis or Brill | Schöningh: +49(o)715413279216| brill@brocom.de 